\title{
SYSTEMATIC REVIEWS
}

\section{Home visits by community health workers to improve identification of serious illness and care seeking in newborns and young infants from low- and middle-income countries}

\author{
A Tripathi ${ }^{1}$, SK Kabra ${ }^{1}$, HPS Sachdev ${ }^{2}$ and R Lodha ${ }^{1}$
}

The objectives of this review were to evaluate the effect of home visits by trained community health workers (CHWs) to successfully identify newborns and young infants (up to 59 days of age) with serious illness and improve care seeking from a health facility. The authors searched the Cochrane Central Register of Controlled Trials, MEDLINE and EMBASE. Abstracts of all articles were read by two authors independently and relevant articles selected. Data were extracted in a pretested questionnaire by two authors independently. Statistical analysis was performed using Review Manager software. A meta-analysis of included randomized controlled trials (RCTs) was carried out. Pooled estimates (risk ratios (RRs) with 95\% confidence intervals (Cls)) of the evaluated outcome measures were calculated by the generic inverse variance method. Seven articles were identified for inclusion in the review. None of them compared the diagnosis of serious illness in young infants by health workers to a 'gold standard' diagnosis. Three studies were available for evaluating the ability of CHWs to identify seriously ill young infants/signs of serious illness. These studies suggest that sensitivity to identify serious illness ranged from 33.3 to $90.5 \%$ and specificity from 75.61 to $98.4 \%$. For the outcome of improved care seeking from a health facility, after pooling the data from six RCTs with 4760 subjects in the intervention and 4398 subjects in the control arm, there was a significant improvement in care seeking in the home visit arm (RR=1.35; $95 \%$ $\mathrm{Cl}=1.15$ to 1.58 ). Moderate quality evidence indicated that home visits by trained CHWs were associated with improved careseeking for sick young infants from health facilities by appropriate health care providers in resource-limited settings. However, there is a lack of data regarding successful identification of serious illness. Evidence from validation studies supports the implementation of home visits by trained CHWs for improving outcomes in sick newborns and young infants in resource-limited areas. Further well-designed studies evaluating the effect of home visits by CHWs on successful identification of seriously ill newborns and young infants should include verification by a 'gold standard'.

Journal of Perinatology (2016) 36, S73-S81; doi:10.1038/jp.2016.34

\section{INTRODUCTION}

High rates of neonatal and early infant deaths from preventable causes are major health concerns, especially in resource-limited countries; lack of awareness, non-identification of the health condition, delay in referral and hesitation in seeking prompt treatment are important contributors. An increasing proportion of child deaths are in sub-Saharan Africa and Southern Asia. ${ }^{1}$ About $73 \%$ of under-five deaths are estimated to be due to acute respiratory infections (mainly pneumonia), diarrheal diseases, prematurity and low birth weight and neonatal infections such as sepsis, birth asphyxia, trauma and malaria. One third of all under-five deaths occur in the neonatal period, the three main causes being prematurity and low birth weight, neonatal infections, mainly sepsis and pneumonia and birth asphyxia and birth trauma. ${ }^{2}$ A World Health Organization report shows that about 44\% of under-five deaths in 2012 occur in the neonatal period. $^{3}$ Three quarters of newborn deaths occur in the first week of life and up to one half (about 2 million) on the first day itself, ${ }^{4}$ and therefore this may be the optimal time for home visits by trained health workers. ${ }^{5}$ The Young Infants Clinical Signs Study
Group reported on the utility of various clinical signs in detection of severe illness in young infants ( $\leqslant 59$ days of age). ${ }^{6}$

Home visits by trained community health workers (CHWs) in the first 2 days of life have been shown to significantly reduce neonatal mortality. ${ }^{7}$ These deaths could be prevented through increased coverage of hospital-based treatment by enhancing availability and access; and by identifying effective treatment for a group of infants with severe infection/serious illness that could potentially be managed at a first level health facility or at the community level, when families do not accept or cannot access referral.

The majority of neonatal deaths can be prevented with quality care during pregnancy and immediate postnatal care. Similarly, most child deaths due to infectious diseases can be prevented by known, simple, affordable and low-cost interventions such as exclusive breastfeeding up to 6 months of age, immunization, appropriate use of antibiotics, oral rehydration therapy and zinc, insecticide-treated bed nets and anti-malarials. ${ }^{3}$ Diarrheal diseases and respiratory infections are the two main infective causes leading to mortality in all regions. ${ }^{2}$ The United Nations in its Millennium Development Goal 4 calls for a two-thirds reduction in

${ }^{1}$ Department of Pediatrics, All India Institute of Medical Sciences, New Delhi, India and ${ }^{2}$ Sitaram Bhartia Institute of Science and Research, New Delhi, India. Correspondence: Dr R Lodha, Department of Pediatrics, All India Institute of Medical Sciences, Ansari Nagar, New Delhi 110029, India. 
the under-five mortality rate by the year $2015 .{ }^{1}$ Several studies have shown the beneficial role of CHWs in reducing neonatal and young infant mortality and morbidity. ${ }^{8,9-10}$ These CHWs can have a key role in early identification and prompt referral of neonates and young infants with danger signs and encourage the community to use health facilities.

Simple management and referral guidelines for common lifethreatening conditions at community and primary health facilities, where referral to hospital is not possible, can potentially save lives. It is unclear whether home visits by trained CHWs improve correct identification of serious illnesses in young infants and their referral to facilities.

The main objective of this review was to evaluate the effect of home visits by trained CHWs to successfully identify newborns and young infants (up to 59 days of age) with serious illness and improve care seeking.

\section{MATERIALS AND METHODS}

Criteria for considering studies for this review

Types of studies. Randomized controlled trials (RCTs), randomized at the level of the individual child or cluster (such as village or district), were included for review. To be eligible, such trials had to have a concurrent comparison group ('no home visits' as an intervention) and adjustment for baseline characteristics and confounders. We only included RCTs with at least one intervention and one control arm.

Types of participants. Children 59 days of age or less in low- and middle-income countries (as categorized by The World Bank by Gross National Income per capita in US dollars, using the Atlas conversion factor). ${ }^{11}$

Types of interventions. The intervention was home visits by CHWs trained to identify serious illness in young infants. According to the World Health Organization, 'CHWs are men and women chosen by the community and trained to deal with the health problems of individuals and the community, and to work in close relationship with the health services. They should have had a level of primary education that enables them to read, write and do simple mathematical calculations'. ${ }^{12}$ The comparison group had no home visits. Studies providing specific additional interventions in both intervention and comparison areas were eligible for inclusion, as long as these additional interventions were similar.

Types of outcome measures. Primary outcomes were:

1. Successful identification of seriously ill young infants

2. Improved care seeking from health facilities.

Search methods for identification of studies

We searched the Cochrane Central Register of Controlled Trials (The Cochrane Library), MEDLINE (from 1966 to 21 October 2014), EMBASE (from 1980 to 12 September 2014). The following search terms were used-'community health worker' AND ('neonate' OR 'infant') AND 'home visits' (Supplementary Table 1). Abstracts of all articles were read by two authors independently and the relevant articles were selected. There were no language restrictions. Experts and researchers in the field were contacted for information on additional completed or ongoing studies as needed. We also performed an electronic lateral search of the references of the selected articles.
Data collection and analysis

Selection of studies. Two authors independently reviewed all titles and abstracts retrieved to assess eligibility according to the inclusion criteria. Full text copies of all potentially eligible papers were obtained. Any disagreements were resolved by mutual discussion, with a third author, if necessary. We selected the studies that fulfilled our criteria. ${ }^{13}$

As data on successful identification of serious illness in newborns and young infants were not available from the RCTs on home visits, we separately searched for studies reporting on the ability of CHWs to successfully identify serious illness/signs of serious illness in newborns and young infants (Supplementary Table 2). These data are reported with sensitivity and specificity.

Data extraction and management. We developed a structured data extraction form to collect relevant information from the selected papers. Data were extracted on to the pretested form by two authors independently. Differences were resolved by discussion with the third author. We collected information about the randomization procedure of the study; setting; participants (the number of patients enrolled and the number of patients assessed); the demographic profile of the population studied (age range and gender); the diagnostic criteria and interventions. Any co-interventions were documented and the data on the outcomes (primary and secondary) were also recorded.

Assessment of risk of bias in included studies. Two review authors independently assessed the risk of bias for each controlled trial using the criteria outlined in the Cochrane Handbook For Systematic Reviews Of Interventions and those recommended by Effective Practice and Organisation of Care. ${ }^{14}$ The judgment for each entry involved assessing the risk of bias as 'low', 'high' or 'unclear', with the last category indicating either lack of information or uncertainty over the potential for bias. Plots of 'risk of bias' assessments were created in RevMan software. ${ }^{15}$ Any disagreements were resolved by discussion.

Measures of treatment effect. Risk ratio (RR) estimations with $95 \%$ confidence intervals $(\mathrm{Cls})$ were used for dichotomous outcomes. ${ }^{16}$

Unit of analysis issues. For cluster RCTs, the stated clusteradjusted RR and $95 \% \mathrm{Cl}$ were used, irrespective of the method employed. ${ }^{16}$

Dealing with the missing data. Where data were missing, we contacted authors in an attempt to obtain them.

Assessment of heterogeneity. We assessed for variability in the participants, interventions and outcomes studied to identify clinical heterogeneity, and for variability in study design to describe methodological diversity. Statistical heterogeneity was identified and measured as recommended by the Cochrane Handbook For Systematic Reviews Of Interventions. ${ }^{17} \mathrm{~A}$ rough guide used for interpretation was:

- 0 to $40 \%$ : might not be important

- 30 to $60 \%$ : may represent moderate heterogeneity

- 50 to $90 \%$ : may represent substantial heterogeneity

- 75 to $100 \%$ : considerable heterogeneity.

As the number of trials included was small (only six), a $P$-value of 0.10 from the $X^{2}$-test was used to determine the statistical significance with regard to heterogeneity.

Assessment of reporting biases. Owing to the small number of studies, we could not evaluate the reporting biases by funnel plot $^{18}$ or conduct formal statistical tests for funnel plot asymmetry, namely the Begg's and Egger's methods. ${ }^{19,20}$ 


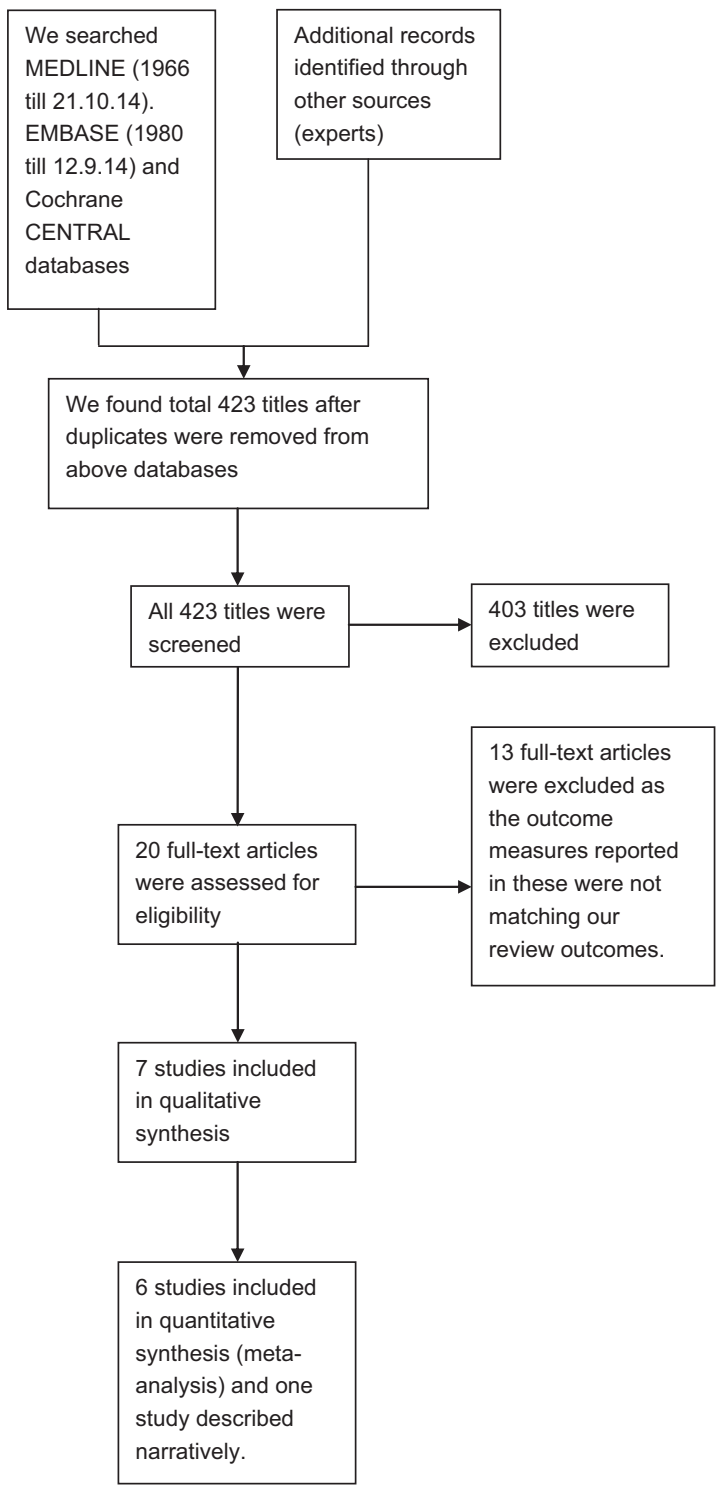

Figure 1. Study flow diagram.

Data synthesis. We performed statistical analysis using Review Manager software (The Nordic Cochrane Centre, The Cochrane Collaboration, Copenhagen, Denmark), and conducted the meta-analysis of included RCTs in concordance with current recommendations. ${ }^{14,15}$ Pooled estimates (RR with $95 \% \mathrm{Cls}$ ) of the evaluated outcome measures were calculated by the generic inverse variance method. We report the $\mathrm{Cl}$ together with the exact $P$-value.

We chose the random effects model in anticipation of expected variations in studies. For studies with more than one intervention arm, we pooled the data from two or more intervention arms for the purpose of final analysis, if the intervention groups had home visits by health workers as one of the components.

\section{RESULTS}

Applying our search strategy, we found 423 titles. After checking reference lists, other sources and consulting experts, the full text of 20 articles was retrieved. Thirteen articles were then excluded as they did not meet our review inclusion criteria. Finally, seven full text articles were included in the review (Figure 1).
Included studies

One of the seven studies included was an individual $\mathrm{RCT}^{21}$ and the other six were cluster RCTs. ${ }^{8,22-26}$ A summary of included studies is shown in Table 1. Two trials ${ }^{8,21}$ had two intervention arms; the other studies had one intervention arm with home visits (and other interventions) and the other control arm with no home visits but similar interventions. All the studies were done in middle- and low-income countries (as categorized by The World Bank by Gross National Income per capita in US dollars, using the Atlas conversion factor $)^{11}$-Bangladesh, Ghana, India (two studies), Pakistan, South Africa and the Syrian Arab Republic. The baseline characteristics of included studies are shown in Supplementary Table 3. The health workers underwent training of some type in all the above-mentioned studies; the duration of training varied from 5 days to 15 months (Supplementary Table 4).

Excluded studies

Thirteen articles with full text were excluded from the review as they did not meet criteria. One study was a prospective follow-up study, not an $\mathrm{RCT}^{27}$ In the rest of the studies, identification and referral of severely ill children was not reported as a study outcome. ${ }^{9,10,28-37}$ A summary of the excluded studies is shown in Table 2.

Risk of bias in included studies

The risk of bias summary for the included studies is shown in Figure 2.

Allocation (selection bias). Randomization was appropriately done in all included studies and rated as 'low risk' for random sequence generation (selection bias). For allocation concealment, only one study ${ }^{21}$ (which was an RCT) was rated as 'low risk'. In the remaining studies the method of allocation concealment was rated as 'high risk'.

Blinding (performance bias and detection bias). Blinding was not achievable in any of the included studies as the two groups were easily identifiable from interviews. We rated studies as 'high risk' for this bias.

Incomplete outcome data (attrition bias). There was 'low risk' of incomplete outcome data in any of the included studies.

Selective reporting (reporting bias). There was 'low risk' of selective outcome reporting in the included studies.

Other potential sources of bias. There was 'low risk' of other possible sources of bias in the included studies.

\section{Effects of interventions}

The included studies evaluated the effect of home visits by CHWs on successful identification of serious illness in neonates and young infants and improved care-seeking at an appropriate health facility (Supplementary Table 5). For studies with more than one intervention $\operatorname{arm}^{8,21}$ the data from the intervention arms were pooled for the purpose of final analysis as all the intervention groups had home visits as one of the components of the intervention. Of the seven selected studies, data from one study were not pooled for meta-analysis ${ }^{26}$ this study was carried out in a high HIV prevalence settingin South Africa. Although some data on identification of illness and care seeking were given in the results, owing to the specific clinical setting and selective reporting of data, we found it inappropriate to pool the data of this study with other studies, so we provided a narrative summary of the results separately. 
Table 1. Characteristics of included studies

\begin{tabular}{|c|c|c|c|c|c|c|c|}
\hline $\begin{array}{l}\text { Study author/ } \\
\text { year/country }\end{array}$ & $\begin{array}{l}\text { Setting/type of health } \\
\text { worker/ period of training }\end{array}$ & $\begin{array}{l}\text { Baseline NMR } \\
\text { or } I M R^{\mathrm{b}} \text { in } \\
\text { control group }\end{array}$ & $\begin{array}{l}\text { Study design/ number } \\
\text { of clusters per arm }\end{array}$ & Study population & Intervention group(s) & Outcome parameters & Comments \\
\hline $\begin{array}{l}\text { Bashour/ } \\
2008^{21} / \text { Syria }\end{array}$ & $\begin{array}{l}\text { Women from a low- } \\
\text { resource developing } \\
\text { country and their } \\
\text { newborns/ registered } \\
\text { midwives/ } 5 \text { days }\end{array}$ & - & Three-arm RCT & $\begin{array}{l}\text { Women who delivered a } \\
\text { healthy newborn whether } \\
\text { by vaginal delivery or } \\
\text { cesarean section, who } \\
\text { lived within } 30 \mathrm{~km} \text { of the } \\
\text { hospital, and who were } \\
\text { available for follow-up for } \\
\text { the next } 6 \text { months. }\end{array}$ & $\begin{array}{l}\text { Women in Group A } \\
\text { received four home visits } \\
\text { on days } 1,3,7 \text { and } 30 \\
\text { following delivery. Women } \\
\text { in Group B received one } \\
\text { home visit on day } 3 \text {. } \\
\text { Group C served as the } \\
\text { control arm. }\end{array}$ & $\begin{array}{l}\text { Maternal postpartum } \\
\text { morbidities; infant } \\
\text { morbidity; uptake of } \\
\text { postpartum care; use of } \\
\text { contraceptive methods; } \\
\text { effect on selected } \\
\text { neonatal health practices. }\end{array}$ & $\begin{array}{l}\text { Results from Group A and } \\
\text { Group B combined as } \\
\text { intervention group for } \\
\text { analysis. }\end{array}$ \\
\hline $\begin{array}{l}\text { Bhutta/ } 2011^{22} \\
\text { /Pakistan }\end{array}$ & $\begin{array}{l}\text { Study was undertaken in } \\
\text { rural Sindh in southern } \\
\text { Pakistan in Hala and Matiari } \\
\text { sub-districts/ LHWs/ } \\
15 \text { days }\end{array}$ & $51.3^{\mathrm{b}}$ & $\begin{array}{l}\text { Cluster randomized } \\
\text { trial/8 }\end{array}$ & $\begin{array}{l}\text { Catchment areas of } \\
\text { primary care facilities and } \\
\text { all affiliated LHWs were } \\
\text { used to define clusters, } \\
\text { which were allocated to } \\
\text { intervention and control } \\
\text { groups by restricted, } \\
\text { stratified randomization. }\end{array}$ & $\begin{array}{l}\text { The intervention consisted } \\
\text { of training LHWs and dais } \\
\text { (traditional birth } \\
\text { attendants) and } \\
\text { promotion of liaison } \\
\text { between them, together } \\
\text { with facilitation of the } \\
\text { creation of voluntary } \\
\text { community health } \\
\text { committees to promote } \\
\text { maternal and newborn } \\
\text { care in their villages. }\end{array}$ & $\begin{array}{l}\text { Perinatal and all-cause } \\
\text { neonatal mortality. }\end{array}$ & \\
\hline $\begin{array}{l}\text { Darmstadt/ } \\
2010^{23} \\
\text { /Bangladesh }\end{array}$ & $\begin{array}{l}\text { Trial was implemented in } \\
\text { Mirzapur, a sub-district of } \\
\text { Tangail district, Dhaka } \\
\text { division/ CHWs and } \\
\text { traditional birth } \\
\text { attendants/36 days }\end{array}$ & $24^{\mathrm{a}}$ & Cluster RCT/6 & $\begin{array}{l}\text { All married women of } \\
\text { reproductive age ( } 15-49 \\
\text { years) in the intervention } \\
\text { arm were eligible for } \\
\text { enrollment }\end{array}$ & $\begin{array}{l}\text { CHWs conducted three } \\
\text { additional postnatal visits } \\
\text { on days } 2,5 \text { and } 8 \text { to } \\
\text { promote preventive } \\
\text { newborn care practices } \\
\text { and to identify and refer } \\
\text { sick neonates to Kumudini } \\
\text { Hospital. }\end{array}$ & $\begin{array}{l}\text { Primary outcome } \\
\text { measures were antenatal } \\
\text { and immediate newborn } \\
\text { care behaviors, knowledge } \\
\text { of danger signs, care- } \\
\text { seeking for neonatal } \\
\text { complications and } \\
\text { neonatal mortality. }\end{array}$ & \\
\hline $\begin{array}{l}\text { Kirkwood/ } \\
2013^{24} / \text { Ghana }\end{array}$ & $\begin{array}{l}\text { The trial, carried out in } \\
\text { Ghana, included all } \\
\text { pregnancies that ended in } \\
\text { a live birth or stillbirth after } \\
\text { Newhints training was } \\
\text { completed/ community- } \\
\text { based surveillance } \\
\text { volunteers/9 days }\end{array}$ & $31^{\mathrm{a}}$ & $\begin{array}{l}\text { Cluster randomized } \\
\text { trial/ } 49\end{array}$ & $\begin{array}{l}\text { All women of } \\
\text { reproductive age (15-45 } \\
\text { years), later restricted to } \\
\text { women who were } \\
\text { pregnant, and their } \\
\text { infants were eligible for } \\
\text { inclusion in the study. }\end{array}$ & $\begin{array}{l}\text { The core component was } \\
\text { training community-based } \\
\text { surveillance volunteers in } \\
49 \text { intervention zones to } \\
\text { identify pregnant women } \\
\text { in their community and to } \\
\text { undertake home visits } \\
\text { (two during pregnancy } \\
\text { and three after birth on } \\
\text { days } 1,3 \text { and } 7 \text { ) }\end{array}$ & $\begin{array}{l}\text { Neonatal mortality rate } \\
\text { and coverage of key } \\
\text { essential newborn-care } \\
\text { practices. }\end{array}$ & \\
\hline $\begin{array}{l}\text { Kumar/ } 2008^{8} \\
\text { /India }\end{array}$ & $\begin{array}{l}\text { Study was carried out in } \\
\text { Shivgarh, a rural block in } \\
\text { Uttar Pradesh/ community- } \\
\text { based health workers, } \\
\text { sakshamsahayaks/ } 7 \text { days }\end{array}$ & $54.2^{c}$ & $\begin{array}{l}\text { A three-arm cluster } \\
\text { RCT/13 }\end{array}$ & $\begin{array}{l}\text { All usual residents of a } \\
\text { household who had } \\
\text { resided in the study area } \\
\text { for } 15 \text { days or more in } \\
\text { succession during the six } \\
\text { months before delivery } \\
\text { and delivered during the } \\
\text { study period were } \\
\text { considered eligible for } \\
\text { inclusion, irrespective of } \\
\text { place of delivery. }\end{array}$ & $\begin{array}{l}\text { One intervention group } \\
\text { received package of } \\
\text { preventive essential } \\
\text { newborn care; other } \\
\text { intervention group } \\
\text { received essential } \\
\text { newborn care plus the use } \\
\text { of a liquid crystal sticker } \\
\text { that indicates } \\
\text { hypothermia; the third } \\
\text { group was the control. }\end{array}$ & $\begin{array}{l}\text { Outcome measures } \\
\text { included changes in } \\
\text { newborn care practices } \\
\text { and neonatal mortality } \\
\text { rate compared with } \\
\text { control group. }\end{array}$ & $\begin{array}{l}\text { The results from two } \\
\text { intervention groups } \\
\text { pooled for final analysis. }\end{array}$ \\
\hline $\begin{array}{l}\text { Mazumder/ } \\
2014^{25} / \text { India }\end{array}$ & $\begin{array}{l}\text { Communities with a } \\
\text { population of } 1.1 \text { million, } \\
\text { served by } 18 \text { primary } \\
\text { health care centers in } \\
\text { Faridabad District, Haryana/ } \\
\text { CHWs/8 days }\end{array}$ & $32.4^{\mathrm{d}}$ & $\begin{array}{l}\text { Cluster randomized } \\
\text { trial/9 }\end{array}$ & $\begin{array}{l}\text { Mother and child pair } \\
\text { registered in IMNCI } \\
\text { programme. }\end{array}$ & $\begin{array}{l}\text { IMNCI intervention } \\
\text { included home visits by } \\
\text { CHWs, improved case } \\
\text { management of sick } \\
\text { children and } \\
\text { strengthening of health } \\
\text { systems. }\end{array}$ & $\begin{array}{l}\text { The pre-specified } \\
\text { outcome was the effect on } \\
\text { care-seeking practices. } \\
\text { Post hoc exploratory } \\
\text { analyses assessed } \\
\text { morbidity, hospital } \\
\text { admission, post-neonatal }\end{array}$ & \\
\hline
\end{tabular}


Studies comparing effect on successful identification of seriously ill young infants

None of the seven studies compared the diagnosis of illness in newborns and young infants made by the CHWs to a 'gold standard' diagnosis. The number of ill children identified in the intervention and control arms was available in six studies. ${ }^{8,21-25}$ The way the studies mentioned the identification of illness in neonates and young infants varied, with three studies mentioning identification of complications or danger signs; ${ }^{8,23,25}$ while the other three did not specifically state the process of identification of illness. ${ }^{21-22,24}$

As the studies did not provide the data for the identification of sick young infants by $\mathrm{CHWs}$, we were unable to synthesize the results. The number of sick young infants reported (a combination of identification by parents, CHWs and other health workers) is likely to be influenced by the effect of the intervention package on the reduction in morbidity in young infants.

In view of the lack of data from the intervention studies evaluating the impact of home visits, we carried out secondary analysis to determine whether trained $\mathrm{CHWs}$ were able to successfully identify sick newborns and young infants. A total of eight studies were found using our search strategy, and the full text of five of these studies was assessed for eligibility. Of these, we identified three evaluating the ability of CHWs to correctly identify serious illness in newborns and young infants. ${ }^{38-40}$ The sensitivity to identify serious illness in these studies ranged from 33.3 to $90.5 \%$ and specificity from 75.61 to $98.4 \%$ (Supplementary Table 5). In a study carried out in rural Nepal to identify optimal sign-based algorithms to define omphalitis in the community and to evaluate the reliability and validity of cord assessments by non-specialist health workers for clinical signs of omphalitis, the sensitivity and specificity of worker evaluations were high for pus (90\% and $96 \%$, respectively) and moderate for redness (57\% and 95\%, respectively). The authors concluded that 'a composite definition for omphalitis that combined pus and redness without regard to swelling was the most sensitive and specific'.41 Two studies were excluded (Supplementary Table 6) as the data for calculating sensitivity and specificity were not available in one ${ }^{42}$ and in the other, the diagnosis made by the female community health volunteer was compared with that made by the facility-based $\mathrm{CHW}$ and not a physician. $^{43}$

Studies comparing the effect on improved care-seeking at a health facility

Data on the effect of home visits by CHWs on improved careseeking at a health facility were available in six studies. ${ }^{8,21-25}$ Data were included for analysis purposes where care-seeking was from an appropriate provider, that is, doctor, nurse or trained paramedical worker. After pooling the data from five studies, care-seeking in the intervention group, that is, the home visit group, was better than in the control arm $(\mathrm{RR}=1.35 ; 95 \% \mathrm{Cl}=1.15$ to 1.58 ) (Figure 3).

One study reported a similar hospitalization rate for diarrhea of $5.7 \%(19 / 334)$ in the intervention arm and 4.5\% (17/378) in the control arm (RR $1.28 ; 95 \% \mathrm{Cl} 0.75$ to 2.19 ). ${ }^{26}$ Among the infants of HIV-infected mothers, similar proportions were tested for HIV infection at 6 weeks $(73.6 \%(420 / 571)$ in the intervention arm as compared with $66.6 \%(465 / 698)$ in the control arm; RR $1.1 ; 95 \% \mathrm{Cl}$ 0.97 to 1.25$)$.

\section{DISCUSSION}

Summary of main results

Seven RCTs fulfilled the inclusion criteria for this review. None of the RCTs compared the identification of seriously ill young infants by trained CHWs with a 'gold standard' diagnosis. As the data from 
Table 2. Characteristics of excluded studies

Awasthi $2008^{27}$

Reason for exclusion Prospective observational study, not RCT. The main outcome measure was to assess symptom-specific care-seeking practices for newborns and behavioral factors associated with them.

Bang $2005^{29}$

Reason for exclusion Key outcomes were stillbirth rate, neonatal mortality rate, perinatal mortality rate, postneonatal mortality rate and infant mortality rate. Data on identification and referral of seriously ill children were not available for the control arm.

Bang $1999^{28}$

Reason for exclusion Key outcomes were neonatal, infant and perinatal mortality rates. Trial did not report on the successful identification of sick young infants in the intervention and control arms.

Baqui $2008^{10}$

Reason for exclusion Primary outcome was reduction in neonatal mortality. Data on identification of ill neonates and care-seeking were available only for the home-care group.

Bhutta $2008^{9}$

Reason for exclusion Key outcomes were effect of intervention on stillbirth, perinatal and neonatal mortality rates. Information on identification and referral/treatment by LHWs was available only in the intervention arm; similar data from the control arm were not reported.

Bonuck $2006^{30}$

Reason for exclusion Intervention was to improve breastfeeding rates; lactation counselor attempted two prenatal meetings, one postpartum hospital and/or home visit, and telephone calls as needed. Main outcome measures were combined outpatient and emergency department visits with illness and breastfeeding-sensitive illness diagnoses. Breastfeeding-sensitive illness visits for otitis media, respiratory tract or gastrointestinal complaints were obtained up to 12 months. Study did not report on the identification and referral of seriously ill children.

Escobar $2001^{31}$

Reason for exclusion Study was conducted in the United States (high-income country). Provided for a home visit by research nurse within $72 \mathrm{~h}$ of discharge of neonate, when discharge was early (within $48 \mathrm{~h}$ of delivery). Primary study outcome was a combined clinical outcome measure considered present if either the mother or the newborn experienced rehospitalization, emergency department or urgent clinic visit use within 10 days after delivery; occurrence of maternal depressive symptoms as documented by a telephone interview 2 weeks after delivery; and/or discontinuation of breastfeeding as documented by a telephone interview 2 weeks after delivery. Hospital-based follow-up in the control arm was compared with the home nurse visit in the intervention arm.

Katz $2011^{32}$

Reason for exclusion Study was conducted in the United States (high-income country). Intervention curriculum designed to improve knowledge, influence attitudes and promote life skills that would assist low-income mothers in offering better health oversight and development for their infants. Study publication does not provide the data on identification and referral of seriously ill young children.

Meghea $2013^{33}$

Reason for exclusion Study was conducted in the United States (high-income country). Main outcome was morbidity (mainly for asthma/ wheezing/croup) among the two groups; data were collected from medical claims and as reported by mother. Study publication does not provide the data on identification and referral of seriously ill young children.

Radcliffe $2013^{34}$

Reason for exclusion Study was conducted in the United States (high-income country). Objective was to describe the partnership with the pediatric community and selected program results. Main outcomes were rates of completed home and primary-care provider visits. Identification and referral of severely ill children not done.

Ransjö-Arvidson $1998^{35}$

Reason for exclusion Subjects in intervention arm received home visits by a midwife on days 3, 7, 28 and 42, while those in control arm received a visit on day 42 postpartum. Key outcomes were infant health problems as perceived by care givers, actions taken to solve infant health problems and mothers' perceived own health problems. Study provided the data on identification of illness in young infants by midwives, mothers and doctors. Data on referral of sick babies were given only for midwives. Comparative data for the infants with one or more health problems as identified by mothers, midwives and doctors were provided only at end of puerperium.

Roux $2013^{36}$

Reason for exclusion Main outcome measure was effect of intervention on 28 measures of maternal and infant well-being among women living with HIV and among all mothers. Article does not report on serious illness and care seeking (except for taking an HIVexposed infant for HIV testing).

Siegel $1980^{37}$

Reason for exclusion Study was conducted in the United States (high-income country). Key outcomes reported were effects of early and extended postpartum contact and paraprofessional home visits on maternal attachment, reports of child abuse and neglect, and health care utilization. Identification and referral of severely ill children not done.

Abbreviations: LHWs, lady health workers; RCT, randomized controlled trials. 
the RCTs on the effect of home visits on outcomes in newborn and young infants did not allow us to evaluate the effect of the intervention on successful identification of seriously ill infants, we reviewed the studies that evaluated the ability of CHWs to identify these infants. These studies show that trained health workers can identify seriously ill children with sensitivity ranging from 33.3 to $90.5 \%$ and specificity from 75.61 to $98.4 \%$. Data for improved care seeking from a health facility were available from six RCTs. Improved care seeking from an appropriate health provider was significantly higher in the intervention group than in the control group ( $R R=1.35 ; 95 \% \mathrm{Cl} 1.15$ to 1.58 ; Figure 3 ) but with high heterogeneity $\left(I^{2}=94 \% ; P<0.00001\right)$.

One study provided information on the hospitalization rate for diarrhea and the proportion of infants of HIV-infected mothers tested for HIV at six weeks; the outcomes were similar in the intervention and control arms. ${ }^{26}$

Overall completeness and applicability of evidence

The findings of our review are consistent with earlier publications that showed a beneficial role of CHWs in promoting maternal and child health and in reducing mother and child mortality rates. $5,9-10,44,45$ There was an evidence of improved care-seeking from an appropriate provider among ill neonates and young infants in the intervention group. We identified seven studies evaluating improved care-seeking from a health facility. There was

\begin{tabular}{|c|c|c|c|c|c|c|c|}
\hline & 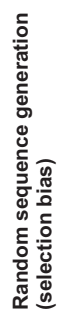 & 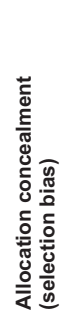 & 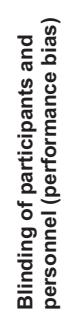 & 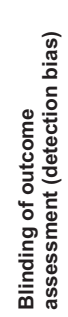 & 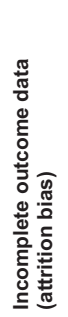 & 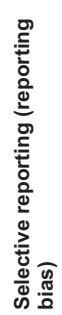 & 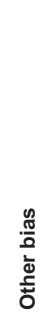 \\
\hline Bashour 2008 (21) & + & + & - & - & + & + & + \\
\hline Bhutta 2011 (22) & + & - & + & - & + & + & + \\
\hline Darmstadt 2010 (23) & + & - & - & - & + & + & + \\
\hline Kirkwood 2013 (24) & + & - & - & - & + & + & + \\
\hline Kumar 2008 (8) & + & - & - & - & + & + & + \\
\hline Mazumder 2014 (25) & + & - & - & - & + & + & + \\
\hline Tomlinson 2014 (26) & + & - & - & - & + & + & + \\
\hline
\end{tabular}

Figure 2. Risk of bias summary: review authors' judgments about each risk of bias item for each included study. substantial variation in clinical settings and relatively high heterogeneity $\left(I^{2}>50 \%\right)$ on pooling the results (Figure 3 ).

The data available from the included studies did not allow us to evaluate the successful identification of serious illness in newborns and young infants as the studies did not have a 'gold standard' for diagnosis to determine sensitivity and specificity. In a few studies, the information about sick children was obtained by interviewing the mother. Reporting of illness in young infants is likely to be influenced by various factors, such as the effect of the home visits program on morbidity and on parents' awareness about illnesses in young infants, and also on the ability of CHWs to successfully identify seriously ill young infants. An optimal study design for assessing the effect of the home visits program should include verification of the diagnosis by a physician or other reliable health worker.

These results were obtained with trained $\mathrm{CHWs}$ in a research setting rather than in an implementation program.

Quality of the evidence

There was a high risk of bias as there was no blinding. We rated the outcomes of improved care seeking as 'moderate quality' (Table 3).

Potential biases in the review process

We assessed all cluster RCTs as 'high risk' for blinding; it was easily identifiable by interviews whether participants belonged to a home visit group or to a non-home visit group. Similarly, allocation sequence concealment was not practical in such studies, giving 'high risk' for this bias (Figure 2).

Agreements and disagreements with other studies or reviews A systematic review in 2010 of controlled trials with five trials satisfying the inclusion criteria concluded that home visits for neonatal care by CHWs were associated with reduced neonatal mortality in resource-limited settings with poorly accessible health facility-based care when conducted along with other community mobilization activities. ${ }^{45}$ In another review in 2013, the authors found moderate to strong quality evidence for the use of CHWs in promoting essential newborn care strategies. ${ }^{44} \mathrm{CHWs}$ were effective in increasing appropriate care-seeking behaviors for newborns by educating mothers on the importance of qualified care.

\section{CONCLUSIONS}

There was moderate quality evidence that home visits by trained CHWs are associated with improved care-seeking for ill young infants to health facilities in resource-limited settings. This evidence provides support for implementation of home visits by

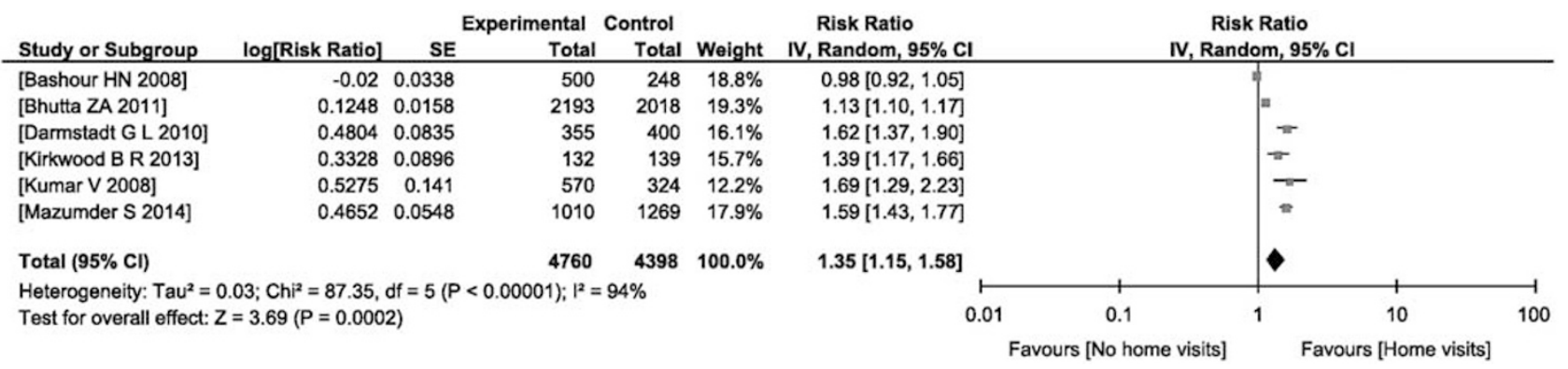

Figure 3. Forest plot of comparison: (1) effect of 'home visits versus no home visits' by community health workers, outcome: (1.1) care-seeking from appropriate health care provider. 
CHWs for improving outcomes of sick newborns and young infants in these areas. Appropriateness of referral may be an issue. Some referrals may be unnecessary (for example, low specificity but high sensitivity), but such a situation may be appropriate for low-resource settings, if the referrals are not so many as to overwhelm the system. It may be better to have high sensitivity in order not to miss any potentially life-threatening illnesses.

Further well-designed studies evaluating the effect of home visits by CHWs on successful identification of seriously ill newborns and young infants verified by a 'gold standard' should be carried out.

\section{CONFLICT OF INTEREST}

The authors declare no conflict of interest.

\section{ACKNOWLEDGEMENTS}

This review was funded by the Department of Maternal, Newborn, Child and Adolescent Health and Development, World Health Organization, Geneva, Switzerland.

\section{REFERENCES}

1 United Nations Millennium Development Goals. Available at http://www.un.org/ millenniumgoals/childhealth.shtml. (accessed on 20 October 2014).

2 WHO.The global burden of disease-2004 update. Available at http://www.who. int/healthinfo/global_burden_disease/GBD_report_2004update_full.pdf?ua $=1$. (accessed on 20 October 2014).

3 WHO. Global Health Observatory: child mortality and causes of death. Available at http://www.who.int/gho/child_health/mortality/en/. (accessed on 20 October 2014).

4 Lawn JE, Cousens S, Zupan J. for the Lancet Neonatal Survival Steering Team 4 million neonatal deaths: When? Where? Why?. Lancet 2005; 365: 891-900.

5 Darmstadt GL, Bhutta ZA, Cousens S, Adam T, Walker N, de Bernis L. Evidencebased, cost-effective interventions: how many newborn babies can we save? Lancet 2005; 365: 977-988.

6 Young Infants Clinical Signs Study Group. Clinical signs that predict severe illness in children under age 2 months: a multicentre study. Lancet 2008; 371: 135-142.

7 Baqui AH, Ahmed S, El Arifeen S, Darmstadt GL, Rosecrans AM, Mannan I et al. Effect of timing of first postnatal care home visit on neonatal mortality in Bangladesh: an observational cohort study. BMJ 2009; 339: b282.

8 Kumar V, Mohanty S, Kumar A, Misra RP, Santosham M, Awasthi S et al. Effect of community-based behaviour change management on neonatal mortality in Shivgarh, Uttar Pradesh, India: a cluster-randomised controlled trial. Lancet 2008; 372: 1151-1162.

9 Bhutta ZA, Memon ZA, Soofi S, Salat MS, Cousens S, Martines J. Implementing community-based perinatal care: results from a pilot study in rural Pakistan. Bull World Health Organ 2008; 86: 452-459.

10 Baqui AH, El-Arifeen S, Darmstadt GL, Ahmed S, Williams EK, Seraji HR et al. Effect of community-based newborn-care intervention package implemented through two service-delivery strategies in Sylhet district, Bangladesh: a cluster-randomised controlled trial. Lancet 2008; 371: 1936-1944.

11 The World Bank. Country and lending groups. Available at http://data.worldbank. org/about/country-classifications/countryand-lending-groups. (accessed on 20 October 2014).

12 WHO. The Primary Health Care Worker: Working Guide. WHO: Geneva, Switzerland, 1990.

13 Moher D, Liberati A, Tetzlaff J, Altman DG. The PRISMA Group Preferred reporting items for systematic reviews and meta-analyses: the PRISMA Statement. PLoS Med 2009; 6: 31000097.

14 Higgins JPT, Green S (eds). Cochrane Handbook For Systematic Reviews Of Interventions Version 5.1.0. The Cochrane Collaboration; 2011.

15 The Cochrane Collaboration. Review Manager (RevMan). The Nordic Cochrane Centre: Copenhagen, Denmark, 2012.

16 Higgins JPT, Green S. Selecting studies and collecting data. Cochrane Handbook for Systematic Reviews Of Interventions. John Wiley \& Sons Ltd.: West Sussex, England: 2008; pp 151-186.

17 Schünemann HJ, Oxman AD, Vist GE, Higgins JPT, Deeks JJ, Glasziou P et al. Chapter 12: Interpreting results and drawing conclusions. In: Higgins JPT, Green S (eds). Cochrane Handbook For Systematic Reviews Of Interventions (Internet). Version 5.1.0. The Cochrane Collaboration; 2011.

18 Sterne JAC, Smith GD. Investigating and dealing with publication and other biases. In: Smith GD. Systematic Reviews In Health Care: Meta-analysis In Context. BMJ Books: London, UK: 2001; pp 189-208. 
19 Sterne JAC, Harbord RM. Funnel plots in meta-analysis. Stata J 2004; 4: 127-141. 20 Sterne JAC, Bradburn MJ, Egger M. Meta-analysis in STATA. In: Egger M, Smith GD, Altman DG. Systematic Reviews in Health Care: Meta-analysis in Context. BMJ Books: London, UK: 2001; pp 347-369.

21 Bashour HN, Kharouf MH, AbdulSalam AA, Asmar KE, Tabbaa MA, Cheikha SA. Effect of postnatal home visits on maternal /infant outcomes in Syria: arandomized controlled trial. Public Health Nurs 2008; 25: 115-125.

22 Bhutta ZA, Soofi S, Cousens S, Mohammad S, Memon ZA, Ali I et al. Improvement of perinatal and newborn care in rural Pakistan through community-based strategies: a cluster-randomised effectiveness trial. Lancet 2011; 377: 403-412.

23 Darmstadt GL, Choi Y, Arifeen SE, Bari S, Rahman SM, Mannan I et al. Evaluation of a cluster-randomized controlled trial of a package of community-based maternal and newborn interventions in Mirzapur, Bangladesh. PLoSOne 2010; 5: e9696.

24 Kirkwood BR, Manu A, ten Asbroek AH, Soremekun S, Weobong B, Gyan T et al. Effect of the Newhints home-visits intervention on neonatal mortality rate and care practices in Ghana: a cluster randomised controlled trial. Lancet 2013; 381: 2184-2192.

25 Mazumder S, Taneja S, Bahl R, Mohan P, Strand T A, Sommerfelt H et al. Effect of implementation of Integrated Management of Neonatal and Childhood Illness programme on treatment seeking practices for morbidities in infants: cluster randomised trial. BMJ 2014; 349: g4988.

26 Tomlinson M, Doherty T, ljumba P, Jackson D, Lawn J, Persson LAK et al. Goodstart: a cluster randomised effectiveness trial of an integrated, community-based package for maternal and newborn care, with prevention of mother-to-child transmission of HIV in a South African township. Trop Med Int Health 2014; 19: 256-266.

27 Awasthi S, Srivastava NM, Pant S. Symptom-specific care-seeking behavior for sick neonates among urban poor in Lucknow, Northern India. J Perinatol 2008; 28: S69-S75.

28 Bang AT, Bang RA, Baitule SB, Reddy MH, Deshmukh MD. Effect of home-based neonatal care and management of sepsis on neonatal mortality: field trial in rural India. Lancet 1999; 354: 1955-1961.

29 Bang AT, Reddy HM, Deshmukh MD, Baitule SB, Bang RA. Neonatal and infant mortality in the ten years (1993 to 2003) of the Gadchiroli Field Trial: effect of home-based neonatal care. J Perinatol 2005; 25: S92-S107.

30 Bonuck KA, Freeman K, Trombley M. Randomized controlled trial of a prenatal and postnatal lactation consultant intervention on infant health care use. Arch Pediatr Adolesc Med 2006; 160: 953-960.

31 Escobar GJ, Braveman PA, Ackerson L, Odouli R, Coleman-Phox K, Capra AM et al. A randomized comparison of home visits and hospital-based group follow-up visits after early postpartum discharge. Pediatrics 2001; 108: 719.

32 Katz KS, Jarrett MH, El-Mohandes AAE, Schneider S, McNeely-Johnson D, Kiely M. Effectiveness of a combined home visiting and group intervention for low income African American mothers: the Pride in Parenting Program. Matern Child Health $J$ 2011; 15: S75-S84.

33 Meghea Cl, Li B, Zhu Q, Raffo JE, Lindsay JK, Moore JS et al. Infant health effects of a nurse-community health worker home visitation programme: a randomized controlled trial. ChildCareHealth Dev 2013; 39: 27-35.
34 Radcliffe J, Schwarz D, Zhao Hon behalf of the MOM Program. The MOM Program: home visiting in partnership with pediatric care. Pediatrics 2013; 132: S153.

35 Ransjö-Arvidson AB, Chintu K, Ng'andu N, Eriksson B, Susu B, Christensson K et al. Maternal and infant health problems after normal childbirth: a randomised controlled study in Zambia. J Epidemiol Community Health 1998; 52: 385-391.

36 Roux IML, Tomlinson M, Harwood JM, O'Connor MJ, Worthman CM, Mbewu N. Outcomes of home visits for pregnant mothers and their infants: a cluster randomised controlled trial. AIDS 2013; 27: 1461-1471.

37 Siegel E, Bauman KE, Schaefer ES, Saunders MM, Ingram DD. Hospital and home support during infancy: impact on maternal attachment, child abuse and neglect, and health care utilization. Pediatrics 1980; 66: 183-190.

38 Bandyopadhyay S, Kumar R, Singhi S, Aggarwal AK. Are primary health workers skilled enough to assess the severity of illness among young infants? Indian Pediatr 2003; 40: 713-718.

39 Baqui AH, Arifeen SE, Rosen HE, Mannan I, Rahman SM, Al-Mahmud AB et al. Community-based validation of assessment of newborn illnesses by trained community health workers in Sylhet district of Bangladesh. Trop Med Int Health 2009; 14: 1448-1456.

40 Darmstadt GL, Baqui AH, Choi Y, Bari S, Rahman SM, Mannan I et al. Validation of community health workers' assessment of neonatal illness in rural Bangladesh. Bull World Health Organ 2009; 87: 12-19.

41 Mullany LC, Darmstadt GL, Katz J, Khatry SK, LeClerq SC, Adhikari RK et al. Development of clinical sign based algorithms for community based assessment of omphalitis. Arch Dis Child Fetal Neonatal Ed 2006; 91: F99-104.

42 Darmstadt GL, Baqui AH, Choi Y, Bari S, Rahman SM, Mannan I et al. Validation of a clinical algorithm to identify neonates with severe illness during routine household visits in rural Bangladesh. Arch Dis Child 2011; 96: 1140-1146.

43 Khanal S, Sharma J, Singh VGC, Dawson P, Houston R, Khadka N et al. Community health workers can identify and manage possible infections in neonates and young infants: MINI-a model from Nepal. J Health Popul Nutr 2011; 29: 255-264.

44 Gilmore B, McAuliffe E. Effectiveness of community health workers delivering preventive interventions for maternal and child health in low- and middle-income countries: a systematic review. BMC Public Health 2013; 13: 847.

45 Gogia S, HPS Sachdev. Home visits by community health workers to prevent neonatal deaths in developing countries: a systematic review. Bull World Health Organ 2010; 88: 658-666B.

(c) (1) This work is licensed under a Creative Commons Attributioncc) NonCommercial-ShareAlike 4.0 International License. The images or other third party material in this article are included in the article's Creative Commons license, unless indicated otherwise in the credit line; if the material is not included under the Creative Commons license, users will need to obtain permission from the license holder to reproduce the material. To view a copy of this license, visit http:// creativecommons.org/licenses/by-nc-sa/4.0/

Supplementary Information accompanies the paper on the Journal of Perinatology website (http://www.nature.com/jp) 